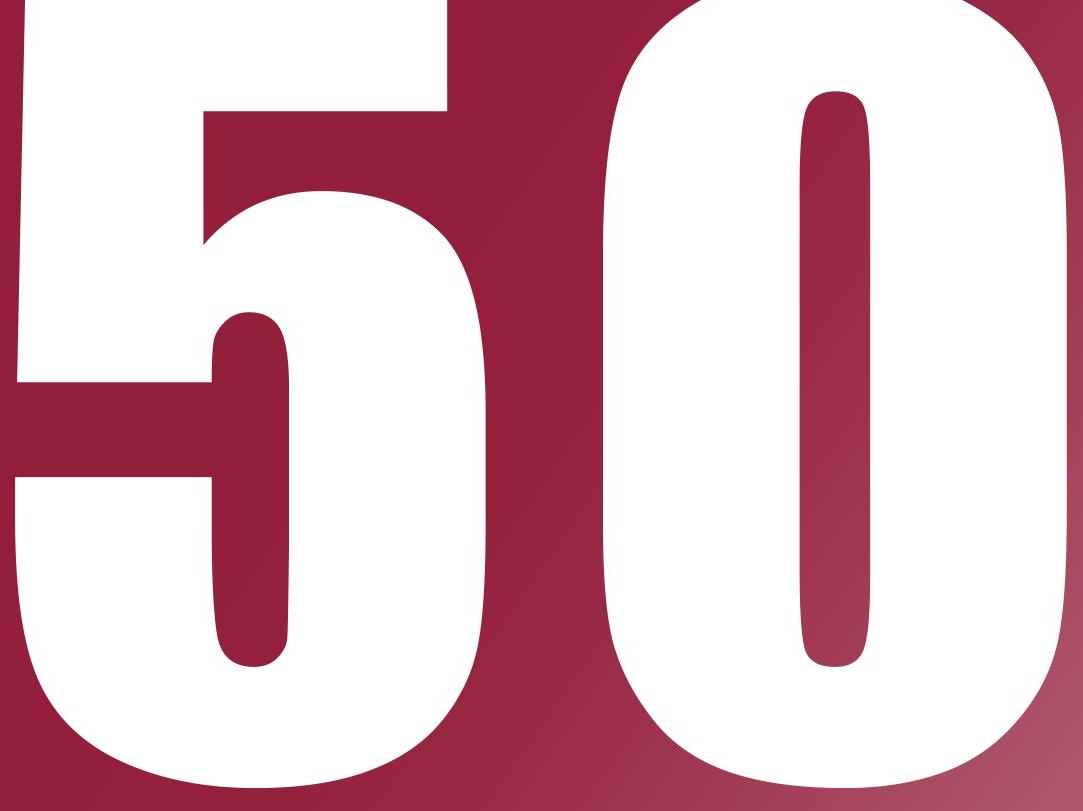

ÁMBITOS

REVISTA

INTERNACIONAL

DE

COMUNICACIÓN

$\mathbf{N}^{\circ} \mathbf{5 0}$

EDICIÓN OTOÑO

2020

ISSN: 1139-1979

E-ISSN: 1988-5733

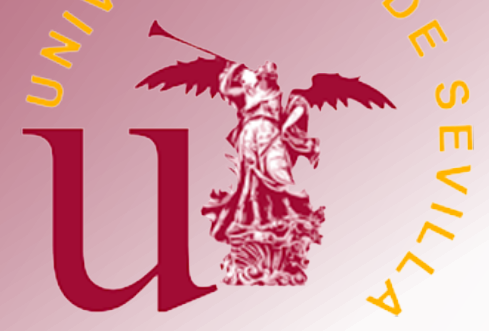




\section{INDICE}

EDITORIAL EDITORIAL

Presentación del Monográfico. Comunicación y juventud. Nuevos medios, representación, recepción y participación en contenidos de entretenimiento e información

Presentation of the monograph. Communication and youth. New media, representation, reception and participation in entertainment and information content.

Juan Francisco Gutiérrez Lozano, Francisco Javier Ruiz del Olmo

7-9

\section{MONOGRÁFICO MONOGRAPH}

El consumo audiovisual de la Generación Z. El predominio del vídeo online sobre la televisión tradicional The audiovisual consumption of Generation $Z$. The predominance of online video over traditional television

La imagen de los jóvenes en las estrategias transmedia de las series de televisión: el caso de Skam España en Instagram

The image of young people in transmedia strategies of TV series: the case of Skam España on Instagram

Sergio Jesús Villén Higueras, Francisco Javier Ruiz del Olmo

La penetración de Netflix en el público español ¿cuestiona el modelo televisivo tradicional?

Does the arrival of Netflix in the Spanish audience challenge the traditional television model?

Javier Bustos Díaz

49-61

Generación Z y consumo de información política: entre la televisión y los nuevos formatos mediáticos Generation $Z$ and consumption of political information: between television and new media formats

Ruth Gómez de Travesedo Rojas, Marta Gil Ramírez

$62-79$

Actualidad y comedia: El éxito de El Intermedio y La Resistencia entre los espectadores jóvenes

Information and comedy: The Success of El Intermedio and La Resistencia for young audiences

Inmaculada Concepción Aguilera García

80-95 
El efecto socializador de articular un espacio de comunidad virtual en el ecosistema del aula

The socializing effect of creating a virtual community space in the classroom environment

Lorea Ariadna Ruiz Gómez, Mónica Hinojosa Becerra, Francisco Javier Ruiz San Miguel

Juventude ciberativista e educação: reflexões sobre um jeito hacker de ser

Cyber activity youth and Education: reflections on a hacker way of being

Carla Azevedo de Aragão, Pietro Matheus Bompet Fontoura Alves, Karina Moreira Menezes

La risa grotesca en la obra de Bob Dylan: análisis de la Bacanal y el Festín Carnavalesco en la trilogía folk-rock eléctrica

Grotesque Laughter in Bob Dylan's Work: Analysis of The Bacchanal and the Carnival Feast in the Electric Folk-rock Trilogy

Jesús Albarrán Ligero

El papel del intertexto en el videojuego. Una partida, mil y una historias

Intertext in video games. A game, thousand and one stories

Rocío Serna-Rodrigo

145-158

\section{ÁmBitos PERSONALES PERSONAL ÁmBITOS}

El auge de Twitch: nuevas ofertas audiovisuales y cambios del consumo televisivo entre la audiencia juvenil The rise of Twitch: New audiovisual offers and the transformation of Television consumption among young audiences

\section{ARTÍCULOS ARTICLES}

La recepción de los medios de comunicación para residentes rusos en la Costa del Sol

Mass media reception by Russian residents on the Costa del Sol

Natalia Meléndez Malavé, José Carlos Pozo García

176-192

La calidad periodística en la cobertura de terremotos: Caso Ecuador

Journalistic quality in earthquake coverage: The case of Ecuador

Juan Pablo Arrobo-Agila, Mendoza María, Ignacio Aguaded

La credibilidad publicitaria en la nueva esfera mediática: los universitarios y los medios

Advertising credibility in the new media sphere: university students and the media 
Arco iris en medios brasileños: percepciones sociales sobre una campaña publicitaria LGBTQIA+

Rainbow in Brazilian media: social perceptions of an LGBTQIA+ advertising campaign

Leonardo Ferreira Batista, José Geraldo de Araújo Ramalho Filho

224-239

Rituales y comunicación política: la toma de posesión de los presidentes autonómicos españoles

Rituals and political communication: the Spanish autonomous Presidents inauguration

Ricardo Domínguez García

240-258

RESEÑAS REVIEWS

Una mirada diferente para hacer periodismo

A different look for making journalism

Guillermo Paredes-Otero

259-261

Periodismo y tecnología: una simbiosis continua

Journalism and technology: a continuous symbiosis

Luisa Graciela Aramburú Moncada

262-265

Una propuesta metodológica para impartir la asignatura de redacción periodística

Journalism and technology: a continuous symbiosis

Noelia Ruiz-Alba

266-268 


\title{
La imagen de los jóvenes en las estrategias transmedia de las series de televisión: el caso de Skam España en Instagram
}

\author{
The image of young people in transmedia strategies of TV series: the case \\ of Skam España on Instagram
}

\author{
Sergio Jesús Villén Higueras \\ Universidad de Málaga | Campus de Teatinos, 9, Málaga 29071 | España \\ | http://orcid.org/0000-0002-6813-3614 | sergio.vh@uma.es \\ Francisco Javier Ruiz del Olmo \\ Universidad de Málaga | Campus de Teatinos, 9, Málaga 29071 | España \\ | http://orcid.org/0000-0002-1953-1798 | fjruiz@uma.es
}

Fechas | Recepción: 25/05/20200 | Aceptación: 19/08/2020| Publicación final: 15/10/2020

\section{Resumen}

La irrupción y posterior incremento de canales y plataformas televisivas en los últimos años ha supuesto también una mayor oferta, variedad y fragmentación de la ficción televisiva, que paralelamente y como estrategia de unión y fidelización de las audiencias ha desarrollado ficciones expandidas en otros medios, planteando diversas estrategias transmedia. Ello es especialmente relevante en las ficciones seriadas dirigidas a los públicos jóvenes, las denominadas teen series, porque se sirven del uso habitual y mayoritario que éstos hacen de determinadas redes sociales como Instagram. En ese contexto el presente artículo ${ }^{1}$ analiza una serie de ficción española protagonizada por personajes jóvenes, utilizando como caso de estudio Skam España (Movistar+, 2018actualidad), y su singular estrategia en Instagram; se trata de un proyecto transmedia nativo en el que resulta destacable cómo se construyen y representan las identidades digitales de los personajes, así como su interacción y actividad en la red. A través del diseño de una plantilla de análisis específica, se

\section{Abstract}

The arrival and subsequent increase of TV channels and platforms in recent years has also enhanced the range, variety and fragmentation of TV fiction that, in parallel and as a strategy for audience joint and fidelity, has developed fictions expanded to other media, coming up with diverse transmedia strategies. This is particularly relevant for serialized fictions aimed at young audiences, the so-called teen series, because these strategies take the main and regular use that young people make of some social networks such as Instagram. In this context, this research analyzes a Spanish TV series starred by teenagers, taking as a case study Skam España (Movistart, 2018-actualidad), and its particular strategy on Instagram. It is a native transmedia project notable for the way in which the character's digital identities are constructed, as well as their interactions and activities around the network. Through the design of a specific analysis template, a content analysis of 1,031 publications from fourteen fictional profiles of this series on

Forma de citar:

Villén Higueras, S. J., Ruiz del Olmo, F. J. (2020). La imagen de los jóvenes en las estrategias transmedia de las series de televisión: el caso de Skam España en Instagram. Ámbitos. Revista Internacional de Comunicación 50, pp. 31-48. doi: 10.12795/Ambitos.2020.i50.03 
ha llevado a cabo un análisis de contenido de 1.031 publicaciones de catorce perfiles ficcionales de dicha serie en Instagram. Entre las conclusiones que se apuntan destacan un especial énfasis en aquellos contenidos que evocan interacciones espontáneas y realistas, una reproducción de arquetipos sociodemográficos y físicos de estos personajes, o también la construcción de identidades digitales de los jóvenes basadas en un yo múltiple y fragmentado que es representado principalmente en contextos urbanos y cotidianos.

Palabras clave: jóvenes, ficción televisiva, redes sociales, perfiles ficcionales, transmedia.
Instagram has been carried out. The conclusions reached includes an special emphasis on those contents evoking spontaneous and realistic interactions, a reproduction of sociodemographic and physical archetypes of these characters, or the configuration of young people's digital identities based on a multiple and fragmentated self who is mainly represented in urban and daily contexts.

Keywords: young, TV fiction, social networks, fictional profiles, transmedia.

\section{INTRODUCCIÓN}

El auge de la ficción televisiva en la última década ha promovido en esta industria el desarrollo y la innovación en la difusión de estrategias transmedia para marcar la diferencia con otros productos culturales. Adaptándose a su naturaleza seriada, muchas experiencias transmedia han explorado e incorporando nuevas fórmulas narrativas y formatos que les permitan extenderse en el tiempo, generar contenidos según las necesidades narrativas y activar la participación de los usuarios. Ante este panorama, el mundo digital se ha convertido en un espacio privilegiado a la hora de construir y modelar estas experiencias (Lacalle, 2013), siendo de especial utilidad las páginas webs, los blogs o las redes sociales. Estos espacios digitales, usados frecuentemente por los espectadores en su vida diaria, se utilizan así para reforzar el realismo y la accesibilidad de los mundos ficcionales (Dena, 2009).

Ahora bien, entre dichos espacios, por su naturaleza social e interactiva, las redes sociales se constituyen como "una nueva vía de unión entre los contenidos televisivos y la audiencia, permitiendo así el desarrollo de universos transmedia" (Cortés, Martínez y De la Fuente, 2016, p. 175). Gracias a estas herramientas comunicativas, por tanto, los usuarios no solo tienen acceso a un flujo dinámico de nanotextos que expanden o sintetizan los relatos adaptándose a las formas de consumo fragmentadas que promueven los dispositivos móviles (Scolari, 2013), sino que también pueden llegar a interactuar con determinados elementos de los mundos ficcionales (Zaccone, 2011).

En este punto, los personajes, considerados elementos fundamentales tanto en la construcción de los mundos ficcionales como en la relación que establece el público con dichos mundos (Evans, 2011), cobran un gran interés para crear estrategias transmedia en las redes sociales. Al transferirlos a estos espacios sociales, los personajes se exponen a un contacto directo con la audiencia y, mediante la actividad de sus perfiles, se fomenta la creación de comunidades y el compromiso de los usuarios (Grandío y Bonaut, 2012; Ortega, 2019). Igualmente es posible mantener una conversación con los personajes, aunque siempre es el usuario quien la inicia 
(Zimmermann, 2015). Por ejemplo, algunas producciones destacadas que han creado perfiles de sus personajes son Misfits (2009-2013), Community (2009-2015), The Lizzi Bennet Diaries (20122013) o Más de 100 mentiras (2018).

A través de estos perfiles, asimismo, se propone una nueva modalidad de recepción que Gauthier (2018) denomina inclusiva, ya que coexiste la ficción con la cotidianeidad digital de los usuarios. Los mundos ficcionales entran así en un estado de permeabilidad constante y usan las redes sociales como una interfaz "que reconfigura no solamente las relaciones entre ficción y realidad, sino también el espacio en el cual estas relaciones se despliegan" (Gauthier, 2018, p. 18).

En base a esta coexistencia, estos perfiles se utilizan a menudo para generar una experiencia multipantalla mediante la sincronización de su actividad con la emisión de la serie o para mantener un contacto más cercano con los espectadores en aquellos espacios vacíos entre capítulos o temporadas. Un ejemplo de estas posibilidades es visible en Cut! (2013-2019), una serie francesa dirigida a adolescentes que creó en Twitter, Facebook y Youtube perfiles de Jules, uno de los personajes principales. Antes del estreno de esta serie, su perfil en Twitter fue lanzado para dar a conocer el personaje y crear expectación con algunos post intrigantes; posteriormente las tres redes se utilizaron para compartir, simultáneamente con la emisión de cada capítulo, contenidos derivados de las prácticas digitales de Jules (tweets, vídeos o fotografías compartidas en directo); y entre capítulos, se ofrecían contenidos inéditos para mantener activa a la audiencia. De este modo los personajes se vuelven parte de la realidad del espectador y dejan de estar definidos únicamente por los códigos propios de la ficción televisiva al adoptar nuevas capas de significado procedentes de su transferencia y representación en las redes sociales.

Si bien cualquier personaje contemporáneo o anacrónico puede ser objeto de esta estrategia transmedia, los perfiles basados en personajes procedentes de producciones dirigidas específicamente a un público juvenil, como las teen series, cobran un especial interés al representar al mismo tiempo uno de los sectores poblacionales que mejor maneja las redes sociales. Si las teen series son productos que permiten "aportar conocimiento sobre qué tipo de imágenes y representaciones de sí mismos pueden consumir los adolescentes" (García y Fedele, 2011a, p. 138), los perfiles derivados de sus personajes, en tanto que extensiones de la ficción en el ámbito digital, se pueden considerar igualmente como nuevos espacios para investigar la representación juvenil.

Esta nueva perspectiva, limitada hasta ahora por la exigua transferencia de personajes ficcionales juveniles a las redes sociales, se ha visto reforzada recientemente por una serie paradigmática en este campo: Skam (2015-2017). De origen noruego, esta producción orientada a los adolescentes destacó tanto por el método de distribución empleado como por su ambiciosa estrategia transmedia en las plataformas sociales (Bengtsson, Källquist y Sveningsson, 2018; Rustad, 2018; Sabina, De la Fuente y Martínez, 2019). 
Aunque la serie fue emitida de forma lineal en NRK (cadena pública de radio y televisión en Noruega), los capítulos fueron fragmentados en clips de vídeo que aparecían en la web de $\mathrm{NRKP}^{2}$ durante la semana en tiempo real. Para conseguir este efecto de sincronización, cada clip de vídeo explicitaba el espacio-tiempo de la acción narrativa al incluir un rótulo con la hora y el día de la semana, siendo en el momento marcado cuando dicha web publicaba el clip. Paralelamente, algunos contenidos complementarios procedentes de las acciones digitales de los personajes en cada clip (fotos, sms o emails) eran publicados en la web de NRKP3 y sus perfiles sociales en Facebook, Instagram o Youtube $^{3}$ se actualizaban.

Consecuentemente, Skam (2015-2017) se puede considerar como un proyecto transmedia nativo, es decir, una narración que desde su inicio es planteada desde una perspectiva transmedia (Costa, 2014), en este caso, con el objetivo principal de conectar con los nuevos hábitos de consumo de los jóvenes y sus costumbres digitales. Gracias a esta visión renovada, los personajes cultivaron sus identidades de una forma más natural y análoga a la de los propios usuarios, lo que plantea nuevos interrogantes sobre qué tipos de contenidos se emplean para modelar estas identidades digitales, cómo son representados los personajes jóvenes en las redes sociales y cuánto tiempo se mantienen activos estos perfiles.

\subsection{Objetivos e hipótesis}

El presente estudio centra su atención en aquellos perfiles ficcionales basados en personajes jóvenes de la ficción televisiva española y tiene como objetivos específicos: detectar qué tipos de contenido se utilizan para construir las identidades digitales de los personajes; analizar cómo son representados los jóvenes a través de los contenidos compartidos en estos perfiles ficcionales; y determinar la duración y los periodos de actividad de dichos perfiles.

A partir de los objetivos establecidos, se plantean en este estudio las siguientes hipótesis:

Hipótesis 1: las identidades digitales de los personajes se nutren de un amplio abanico de contenidos de naturaleza diversa, prevaleciendo aquellos que provocan un efecto de espontaneidad y realismo.

Hipótesis 2: los perfiles de los personajes reproducen en gran medida los arquetipos sociodemográficos, físicos y sexuales habituales en este tipo de series, aunque proponen algunas redefiniciones.

Hipótesis 3: los personajes proyectan en sus perfiles un yo múltiple y fragmentado a través de representaciones directas e indirectas en marcos contextuales asociados principalmente a su vida cotidiana.

Hipótesis 4: la duración de estos perfiles varía según la función de cada personaje en la serie y su actividad se concentra principalmente durante la emisión de cada temporada para proyectar una imagen más amplia y realista de los personajes. 


\section{DELIMITACIONES Y METODOLOGÍA}

Tomando como punto de referencia la ficción española protagonizada por personajes jóvenes, se ha seleccionado como caso de estudio Skam España (Movistart, 2018-actualidad), un remake de la serie noruega Skam (2015-2017) que, en su adaptación a la exitosa estrategia transmedia original, ha creado en Instagram, una de las redes sociales más populares entre los jóvenes españoles (IAB Spain, 2019), catorce perfiles públicos ${ }^{4}$ basados en sus personajes principales y secundarios. Respecto al periodo de tiempo seleccionado para el análisis, éste abarca todas las publicaciones de estos perfiles durante las tres primeras temporadas. Así pues, la composición de la muestra es todo el universo de mensajes en Instagram de dichos perfiles, formado por 1.031 publicaciones; por tanto, no se llevó a cabo muestreo.

Para la exploración de estos perfiles se ha llevado a cabo un análisis de contenido, por lo que se ha empleado un método mixto cualitativo y cuantitativo que pone el foco de atención en tres ejes: la naturaleza de los contenidos compartidos, la representación de los personajes y el periodo de actividad de cada perfil. Los datos se han recolectado mediante la siguiente plantilla de análisis:

Tabla 1

Variables de análisis

\begin{tabular}{|c|c|}
\hline $\begin{array}{l}\text { Naturaleza de los } \\
\text { contenidos }\end{array}$ & $\begin{array}{l}\text {-Espacio de la publicación: feed o stories. } \\
\text {-Tipo de contenido: } \\
\text { a) Generados por los propios personajes: fotografías, vídeos, GIF, dibujos, } \\
\text { etc. } \\
\text { b) Contenidos procedentes de la cultura en Internet (ilustraciones, } \\
\text { fragmentos de texto, memes, etc.), las industrias culturales (contenidos } \\
\text { de series, películas, videojuegos, artistas musicales, etc.) o los medios de } \\
\text { comunicación (imágenes o vídeos informativos). } \\
\text {-Edición de contenidos: uso de filtros y efectos visuales. }\end{array}$ \\
\hline $\begin{array}{l}\text { Representación de } \\
\text { los personajes }\end{array}$ & $\begin{array}{l}\text {-Información sociodemográfica: género, rasgos raciales y religión. } \\
\text {-Características físicas: delgado, normal o musculoso. } \\
\text {-Preferencias sexuales: heterosexuales, homosexual-lésbico o homosexual- } \\
\text { gay. } \\
\text {-Representación de los personajes en base a las categorías identificadas por } \\
\text { Caldeira (2016): } \\
\quad \text { a) Directas: representación del yo y representación mixta. } \\
\text { b) Indirectas: representación del otro y objetos. } \\
\text {-Contexto: ambiente-ocio, cotidiano, urbano, natural y otros. }\end{array}$ \\
\hline $\begin{array}{l}\text { Periodo de } \\
\text { actividad del perfil }\end{array}$ & -Fecha de publicación de cada contenido. \\
\hline Seguidores de perfil & -Número total de seguidores que acumula cada perfil. \\
\hline
\end{tabular}

Fuente: elaboración propia.

Para la elaboración de la matriz de análisis de contenido y de sus variables, se han seguido las investigaciones de García y Fedele (2011b) y Caldeira (2016) para explorar las formas de representación de los personajes, a las que sumamos otras de elaboración propia, coincidentes con elementos buscados en los objetivos del texto, sobre la naturaleza de los contenidos. 


\section{RESULTADOS}

\subsection{El ecosistema de contenidos en los perfiles ficcionales}

Los personajes ficcionales utilizan Instagram como una memoria en la que almacenan y comparten contenidos de diversa naturaleza, origen y autoría, configurando así una identidad mosaico (Caro, 2012) caracterizada por la fragmentación del discurso. Así pues, se han contabilizado un total de 1.031 teselas, de las cuales el $59,75 \%$ se ha publicado en el feed, es decir, la página inicial que ofrece una vista general de los post, y el $40,25 \%$ se ha llevado a cabo en las stories, una función que permite compartir contenidos de una manera más espontánea.

Según la actividad que ha mantenido cada género, los perfiles femeninos se muestran más activos al publicar el $75,07 \%$ de los contenidos analizados.

En relación a los tipos de contenido, el $97,77 \%$ son producciones propias, por lo que la identidad digital de los personajes queda definida por aquello que crean y publican y no tanto por producciones ajenas obtenidas de otros espacios digitales.

Dentro de los contenidos de producción propia, destaca en los perfiles de ambos géneros una preferencia por las fotografías (ver gráfico 1). Al tratarse de una red social visual pensada para capturar y compartir imágenes en cualquier momento con un dispositivo tan personal como el móvil, las fotografías que aparecen en estos perfiles transmiten una espontaneidad y un aire de autenticidad que reformula la manera en la que el público se relaciona con el mundo ficcional de Skam España. Los personajes desarrollan así en tiempo real su identidad digital y difuminan la línea que separa la realidad de la ficción aprovechando que, "con Instagram, el noema de la fotografía se ha desplazado al 'este soy yo', acelerando el Tiempo de la fotografía hacia el presente, no el pasado. Se captura lo que se vive, no lo que se quiere detener ni capturar" (Cantón, 2019, p. 129).
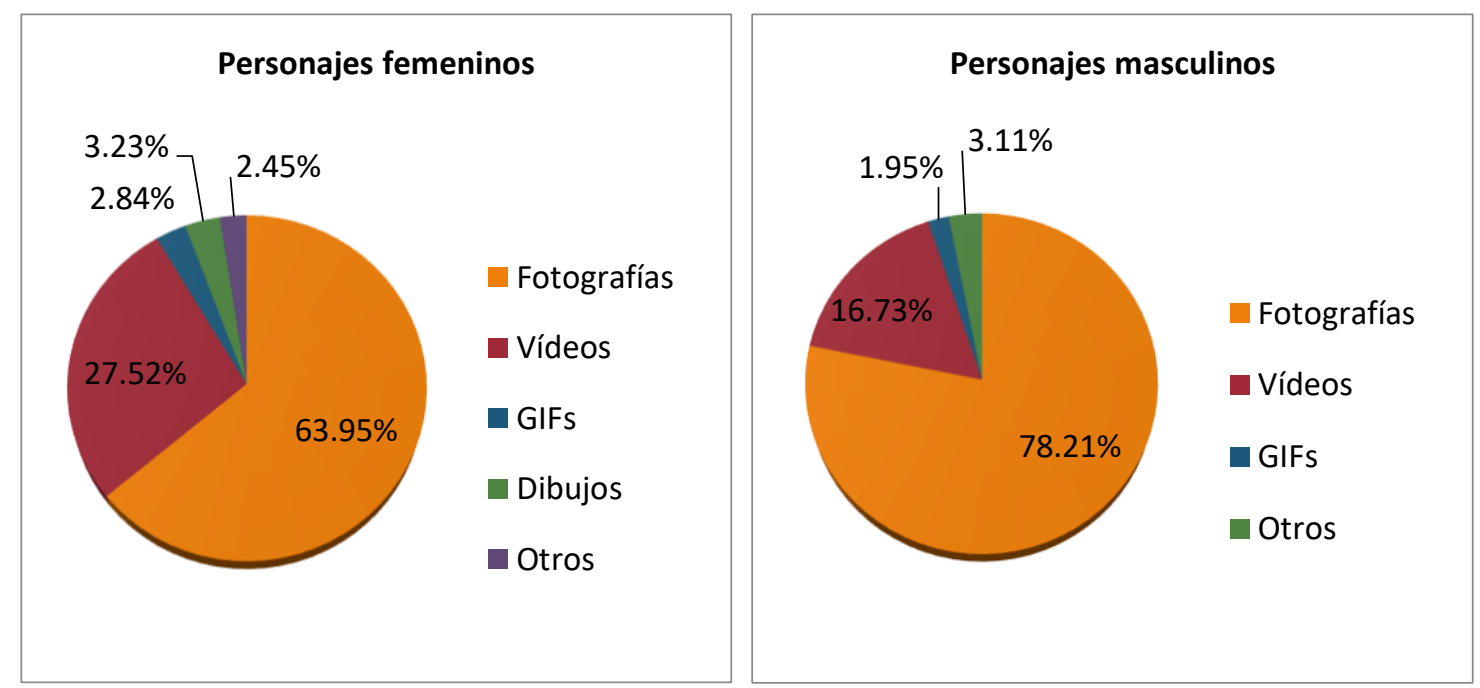

Gráfico 1. Contenidos publicados según el género de los personajes ficcionales

Fuente: elaboración propia. 
Otro tipo de contenido popular en esta plataforma, los vídeos, se encuentran en su mayoría en los stories de los personajes y son más comunes en los perfiles femeninos (28\%) que los masculinos (16,73\%). Todos los vídeos analizados son de corta duración (normalmente inferiores a los 15 segundos) y adoptan cánones estéticos propios de Instagram al representar fragmentos crudos y espontáneos de los personajes y su mundo ficcional. Excepcionalmente se ha detectado un vídeo más largo publicado a través del IGTV (Instagram TV) de un perfil que muestra la intervención musical de un personaje en la serie.

Junto a las fotografías y los vídeos, aunque con menor frecuencia en ambos géneros, se encuentran también GIFs, imágenes con textos propios, capturas de pantalla o dibujos personales que enriquecen y atomizan sus identidades digitales.

Desde el punto de vista de los contenidos publicados que no han sido creados por los propios personajes, que representan el 2,23\% (estos contenidos forman parte del apartado "otros" del gráfico 1), se encuentran principalmente en ambos géneros imágenes e ilustraciones con texto. En cambio, otros fragmentos procedentes de la cultura en Internet, las industrias culturales o los medios de comunicación, que permiten definir también la identidad digital de los usuarios (Caro, 2012), apenas son usados en esta estrategia transmedia. Como excepciones, sólo dos personajes femeninos (Nora y Eva) han optado por compartir este tipo de contenidos, en concreto, una noticia sobre política de un medio estadounidense y un webcomic de Sarah Andersen.

En cuanto a la edición de los contenidos, los personajes de ambos géneros han usado algún tipo de filtro o efecto visual en el $22,86 \%$ de las imágenes fotográficas y el $47,65 \%$ de los vídeos. Con estas capas de significado propias de Instagram, los personajes proyectan un comportamiento naturalizado al experimentar y divertirse con las diferentes posibilidades de edición digital que ofrece esta plataforma.

De los contenidos editados, asimismo, son de especial interés aquellos que incorporan stickers de los stories con preguntas o encuestas tipo A o B para fomentar la participación de los usuarios (ver imagen 1). En el primer caso, por ejemplo, dos personajes (Eva y Amira) subieron una fotografía con este tipo de sticker para preguntarle a sus seguidores propuestas de pancartas para la manifestación del día internacional de la mujer (8M). Tras lanzar esta cuestión, ambos personajes aparecen en una serie de fotografías en las que incluyen stickers con las propuestas más originales. En el segundo, el sticker tipo encuesta se utilizó en otra cuenta (Cristina) con el fin de encontrar un shipname (acrónimo basado en nombres de persona) atractivo en base a los nombres de dos personajes (Viri y Alejandro). Mediante este tipo de stickers, por consiguiente, se invita a los seguidores a interactuar con los personajes y formar parte de su cotidianeidad digital. 

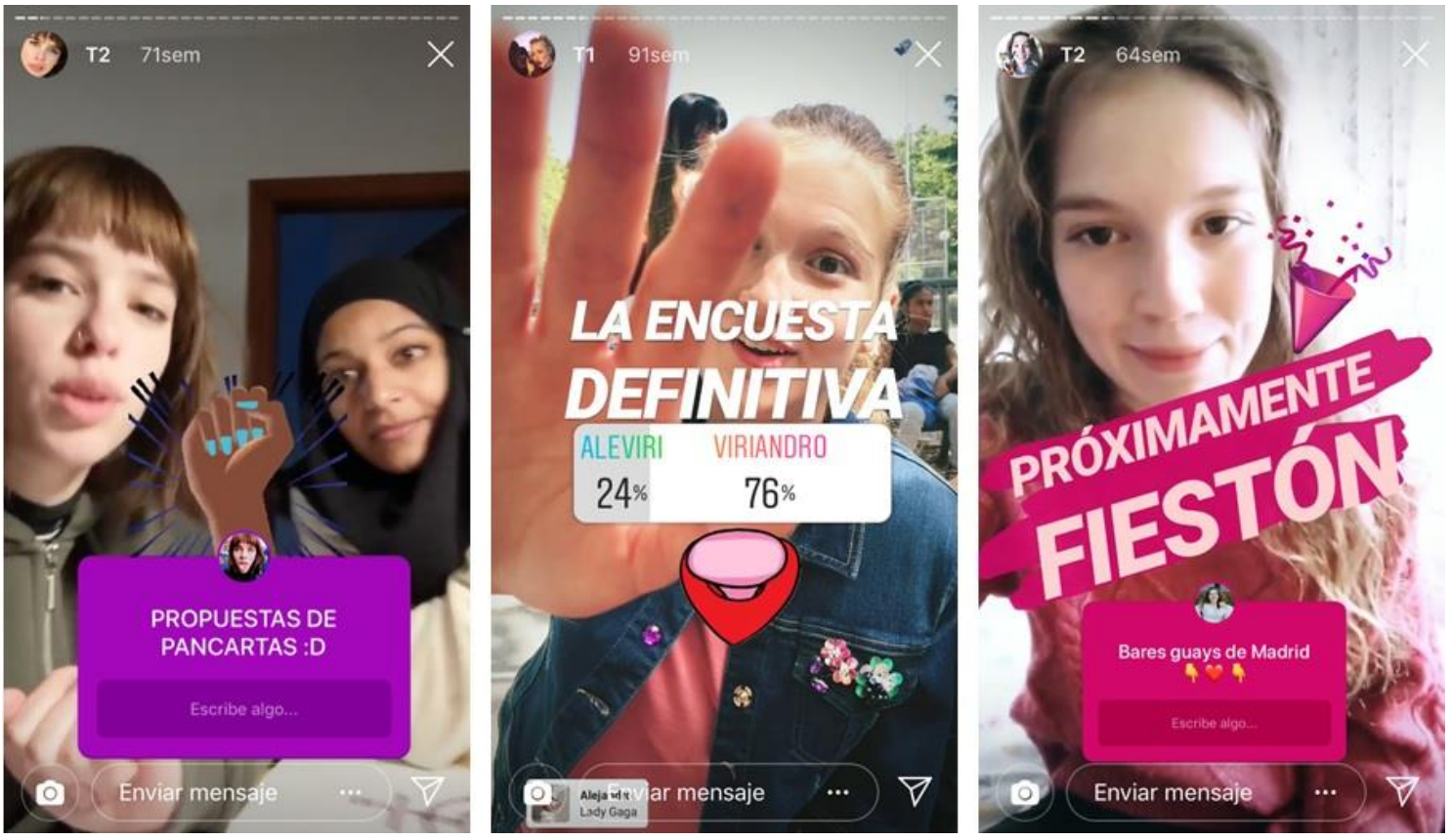

Imagen 1. Contenidos con stickers para activar la participación de los usuarios Fuente: perfiles oficiales en Instagram de los personajes Eva, Cristina y Elvira.

\subsection{La representación de los personajes jóvenes}

A lo largo de su estrategia transmedia en Instagram, Skam España ha acumulado el mismo número de perfiles para ambos géneros de personajes, aunque no todas las temporadas han mantenido activos un número igualitario. Las dos primeras temporadas cuentan con un número superior de perfiles femeninos ( $60 \%$ y $63,6 \%$ respectivamente), mientras que en la tercera se establece una equidad al incorporarse nuevos personajes masculinos. Este resultado, consecuentemente, afecta al número de seguidores acumulado, siendo el de ellas $(842,7 \mathrm{k})$ mucho mayor que el de ellos $(439,6 \mathrm{k})$.

Según los rasgos raciales de los personajes que comparten y aparecen en los contenidos, se detecta una sobrerrepresentación de jóvenes caucásicos (95,65\%), frente a una minoría árabe $(3,58 \%)^{5}$ y mestiza $(0,77 \%)$. Estos resultados refuerzan así el protagonismo de aquellos personajes adolescentes más frecuentes en la ficción televisiva española: blancos como raza predominante y la presencia periférica de personajes de otras razas (Guarinos, 2009).

Los datos obtenidos indican además una desconexión generalizada entre los perfiles de los personajes ficcionales y la religión. El $96,8 \%$ de los contenidos no contiene ningún tipo de información sobre las creencias religiosas. Este dato viene a confirmar y reforzar la pérdida de protagonismo que ha sufrido la religión, especialmente la católica, en la ficción televisiva española (Ramos y Fernández, 2011). El porcentaje restante corresponde íntegramente al perfil de Amira, un personaje femenino que expande su identidad como musulmana en su perfil social al aparecer representada con el hiyab, prenda utilizada por las mujeres de esta religión, y la publicación de algunas fotografías sobre el Corán, el Ramadán Mubarak o el Centro Cultural Islámico de Madrid. 
Atendiendo a su constitución física, se observa en aquellos contenidos que muestran una presencia corporal de los personajes una relación con los cánones físicos que suelen predominar en estas series (García y Fedele, 2011b) al representar personajes de complexión delgada $(23,37 \%)$, normal $(66,09 \%)$ y musculosa $(10,53 \%)$. Estos porcentajes, no obstante, son dispares según el género, ya que los personajes delgados son todos femeninos y los musculosos masculinos. A pesar de esta búsqueda estética en la complexión física, los personajes aparecen principalmente vestidos y con ropa carente de connotaciones sexuales (por ejemplo, vestimenta ajustada, transparencias o lencería visible). Aun así, se detectan algunas representaciones estereotipadas al aparecer ellos sin camiseta para destacar su musculatura en el 3,31\% de los contenidos y ellas en el $0,88 \%$ exhiben gran parte de su cuerpo en algunas fotografías en bañador.

Adicionalmente, todos los personajes, excepto Amira, expresan sus preferencias sexuales, las cuales se visibilizan en el $13,12 \%$ de los contenidos analizados. De este porcentaje, a su vez, se observa una ruptura con el discurso heterosexual predominante (Lemoine, 2013) al plantear un panorama diferente de inclinaciones sexuales: homosexual-lésbicas $(52,05 \%)$, heterosexuales $(45,20 \%)$ y homosexual-gay $(2,73 \%)$.
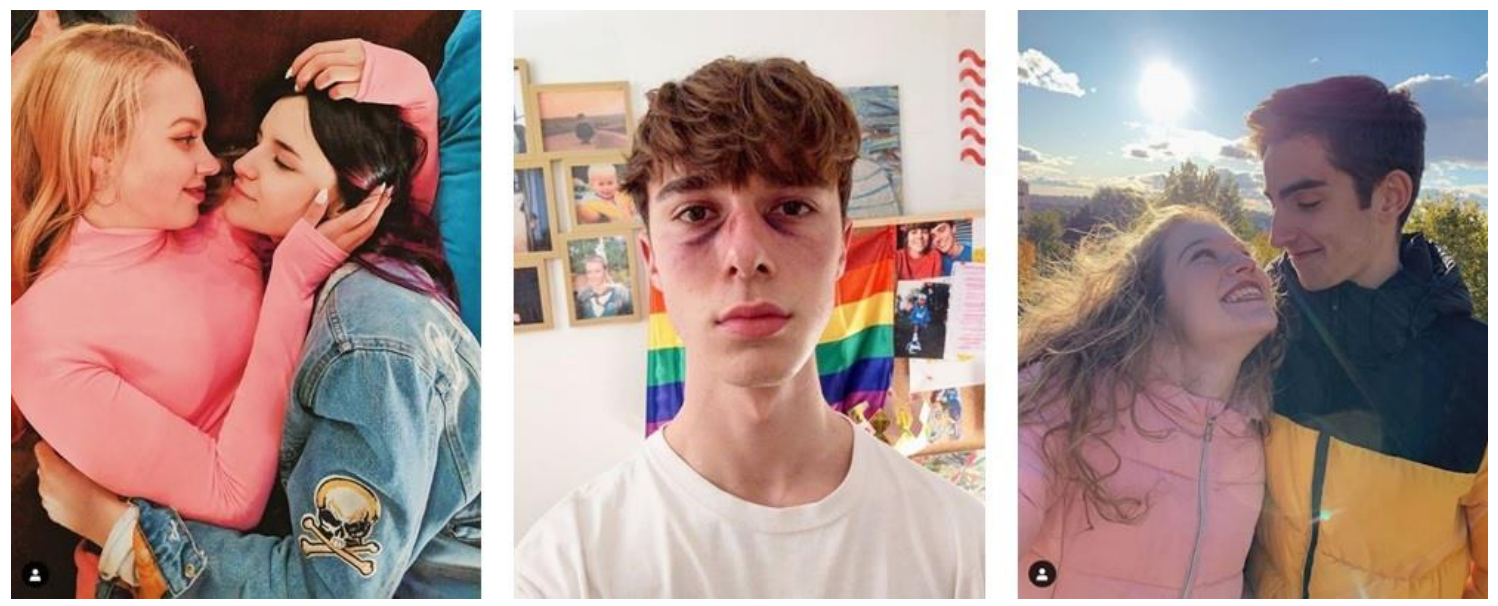

Imagen 2. Imágenes de los personajes en las que muestran sus preferencias sexuales

Fuente: perfiles oficiales en Instagram de los personajes Cristina, Lucas y Hugo.

Para la manifestación de estas preferencias, se usan mayoritariamente imágenes en las que expresan su afecto y conexión con algún personaje (miradas íntimas, gestos cariñosos, abrazos o textos con algún emoji amoroso) sin llegar, en ningún caso, a mostrar un contacto físico directo entre sí. Si bien esta es la dinámica general, se observa también una búsqueda de la identidad sexual marcada por la reivindicación y la lucha por romper con la matriz heterosexual. Es el caso de Lucas, un personaje que proyecta su orientación homosexual en Instagram a través de símbolos, como la bandera LGTBI (también con emojis o textos con los colores característicos) y la imagen de Gaysper, o con fotografías en las que denuncia una agresión homofóbica sufrida. Este perfil funciona así como un espacio social que promueve la liberación sexual del personaje, su identificación con aquellos fenómenos y símbolos reivindicativos forjados en la cultura digital online y la lucha social contra la discriminación sexual. 


\subsubsection{La construcción de la identidad digital de los personajes}

En sus perfiles de Instagram, los personajes atomizan su identidad representado un yo heterogéneo y fragmentado. La experiencia transmedia ofrecida es un collage de contenidos variados que va configurando un relato personal de cada personaje desde múltiples ángulos. Cada fragmento forma así parte de un todo, la identidad digital del personaje, que va acumulando significados mediante diferentes formas de representación.

Estas formas están estrechamente vinculadas a la naturaleza del elemento representado en cada contenido, que, en base a las categorías identificadas por Caldeira (2016), se corresponden con: la representación del yo (protagonista del perfil); el otro (otro personaje ficcional); mixta (relaciones del protagonista del perfil con otros personajes ficcionales); y objetos (como por ejemplo objetos inanimados, animales, paisaje, comida, etc.). Como apunta Caldeira (2016), las categorías referentes al otro y los objetos son formas de representación indirectas, mientras que las dos restantes, en las que se visibiliza el cuerpo del sujeto, son representaciones directas. Partiendo de esta categorización, según los objetos representados en los contenidos compartidos por los personajes, se encuentra que sus identidades digitales se configuran de la siguiente manera:

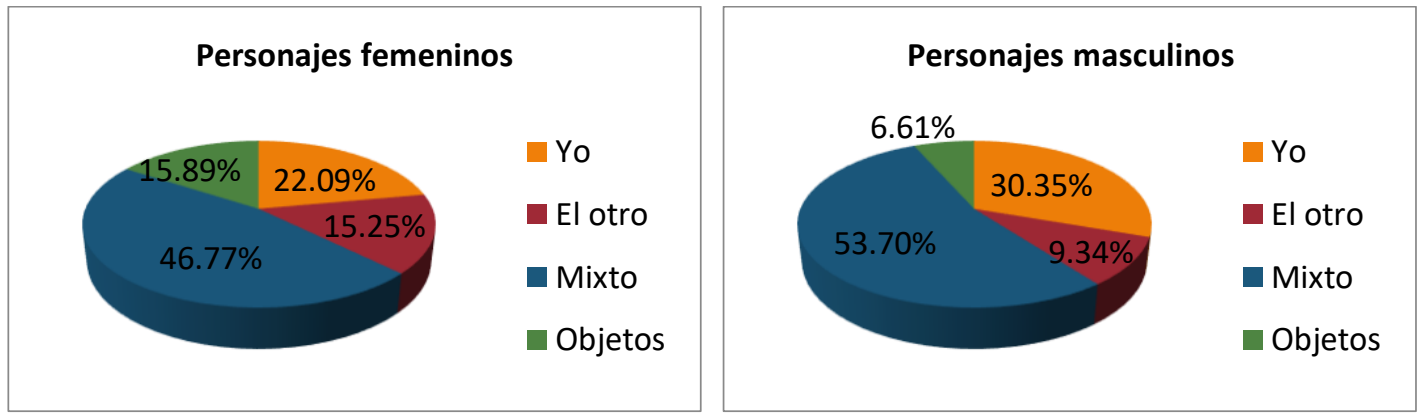

Gráfico 2. Elementos representados en los contenidos publicados por los personajes

Fuente: elaboración propia.

a) La representación del yo: los personajes femeninos publican menos contenidos centrados en su yo $(22,09 \%)$ que los masculinos (30,35\%). La intención de esta forma de representación es marcar explícitamente su presencia, exhibirse como los únicos protagonistas para provocar el efecto que buscan los usuarios en esta plataforma: "aparecer para ser" (Sibilia, 2013, p. 130). Esta búsqueda de presencia justifica la exhibición frecuente de cada personaje y su yo epidérmico, el cual, al mismo tiempo, refuerza la simulación de su existencia. Destaca, a su vez, la construcción de un yo constituido por unidades corporales que faciliten en todo momento su reconocimiento, siendo excepcionales las representaciones metonímicas, es decir, fragmentos específicos del cuerpo (Caldeira, 2016).

En esta categoría se encuentra también la búsqueda de un yo estético y subjetivo a través de fotografías y vídeos realizados por los propios personajes, es decir, selfies. A través de ese formato, usado en el $9,04 \%$ de los contenidos publicados por ellas y en el $8,17 \%$ por ellos, los personajes transfieren enunciaciones en primera persona y proponen una autonarrativa en tiempo real, ya que, como apunta Leonardo $(2019$, p. 117) "las dinámicas de circulación y 
decodificación de la selfi parten de sobreentender que eso que vemos en la imagen está sucediendo ahora mismo". A través de esta evocación del presente, el aquí y ahora, estos contenidos potencian un modo de consumo desprogramado y espontáneo en el que los hechos ficcionales transcurren de forma simultánea a la realidad de los usuarios.

En contraste con los autorretratos, que promueven la construcción de biografías lineales de los personajes en tiempo real, también se han encontrado contenidos que representan su yo en el pasado. Estas disrupciones secuenciales se detectan en algunas imágenes que representan a los personajes de Nora e Inés durante su infancia, las cuales amplían sus líneas temporales fuera de la diégesis mediante flashbacks que se reducen, en este caso, a una fotografía.

Desde otro punto de vista, el despliegue del yo incluye capas de significado adicionales procedentes de aquellos elementos complementarios que acompañan a los personajes (vestimenta, tecnología, alimentación, entretenimiento, etc.) para reflejar sus personalidades, estilos o preferencias. Si bien el objetivo principal de tales elementos es inyectar nuevos significados que amplíen la definición de los personajes, también pueden tener una finalidad alternativa: la inclusión de un producto real con fines promocionales.

Este tipo de estrategia publicitaria, conocida como emplazamiento de producto, aprovecha en este caso la comunidad de seguidores que sustenta un determinado personaje ficcional, así como su cercanía con la audiencia joven, para captar la atención de potenciales clientes. El emplazamiento de un producto asociado a la presentación del yo se observa en dos fotografías de la cuenta de Cristina ${ }^{6}$ que muestran al personaje sujetando una botella de vodka Eristoff en diferentes situaciones divertidas. Así, el objeto publicitario participa de forma explícita en la construcción de la identidad digital de este personaje a la vez que se promociona entre su comunidad de seguidores.

En último lugar, si bien el yo de cada personaje se construye y se proyecta principalmente desde la perspectiva de la ficción televisiva, en algunos casos trasciende esta limitación rompiendo la denominada quinta pared, es decir, "el personaje toma como suya la realidad, participa y opina sobre hechos actuales" (Ortega, 2019, p. 109) en las redes sociales. Algunos ejemplos de esta ruptura entre la ficción y la realidad se observan en el story de Lucas, que se dirige a sus seguidores en un vídeo para que voten en las elecciones generales de España de abril de 2019, o en el story de Nora, que hace un llamamiento con seis vídeos selfies cortos para que sus seguidores se movilicen y asistan a la manifestación del 8M de 2019. De este modo Instagram se constituye como una interfaz bidireccional que permite a los usuarios interactuar con la ficción y a los personajes interceder en la realidad. El yo de los personajes propuesto en estos perfiles, consecuentemente, puede definirse alternando referentes procedentes de ambos mundos.

b) La representación del otro: la cesión de espacio y atención única a otros personajes aparece en el $15,25 \%$ de los contenidos que comparten ellas y en el 9,34\% de ellos. Aunque aparecen con menor frecuencia, se observa que la huella del otro puede tener como propósitos: fortalecer los vínculos entre los personajes y manifestar sus propios puntos de vista sobre el otro; mostrar 
momentos divertidos y efímeros de sus interacciones sociales, lo cual connota la habilidad y la atención de cada personaje; filtrar algún momento íntimo del otro para generar tensiones en torno a la privacidad; o transmitir una experiencia colectiva, como uno de los vídeos subidos al story de Eva en el que capta una multitud de gente (los otros) en la manifestación del 8M. En este último caso la representación del otro se convierte en una potente estrategia de desficcionalización al ver los seguidores de estas cuentas su propia realidad desde la perspectiva de un personaje ficcional.

c) Representación mixta: considerando la naturaleza social de esta plataforma, este tipo de representación es la más común al reflejarse en el $46,77 \%$ de los contenidos compartidos por ellas y en el $53,70 \%$ de ellos. Profundizando en el tejido social que aglutinan estos porcentajes (ver gráfico 3 ), se obtienen varios resultados de interés: las relaciones entre personajes del mismo género son las más habituales en todas las cuentas analizadas, aunque ellas muestran un porcentaje superior $(60,22 \%)$ frente a ellos $(43,48 \%)$; hay una representación estereotipada en cuanto a las relaciones con el género opuesto, ya que los personajes femeninos aparecen menos junto a amigos (6,35\%), siendo Lucas el más frecuente, que los masculinos con amigas (26,09\%); ambos géneros aparecen representados de forma muy similar junto a sus parejas y grupos de amigos; las relaciones familiares apenas tienen visibilidad en estos perfiles, siendo solo representados algunos personajes femeninos junto a algún familiar (1,93\%). A tenor de estos datos se revela, por un lado, que el contacto con los pares, considerados como el principal agente socializador durante la adolescencia (Merino, 2011), vertebra la mayoría de interacciones sociales de los personajes y, por otro, que los aspectos clave en la construcción de la identidad de los personajes jóvenes de las teen series, como la amistad, el amor y las relaciones establecidas por el grupo de amigos (García y Fedele, 2011b), son también prioritarias en sus perfiles sociales.

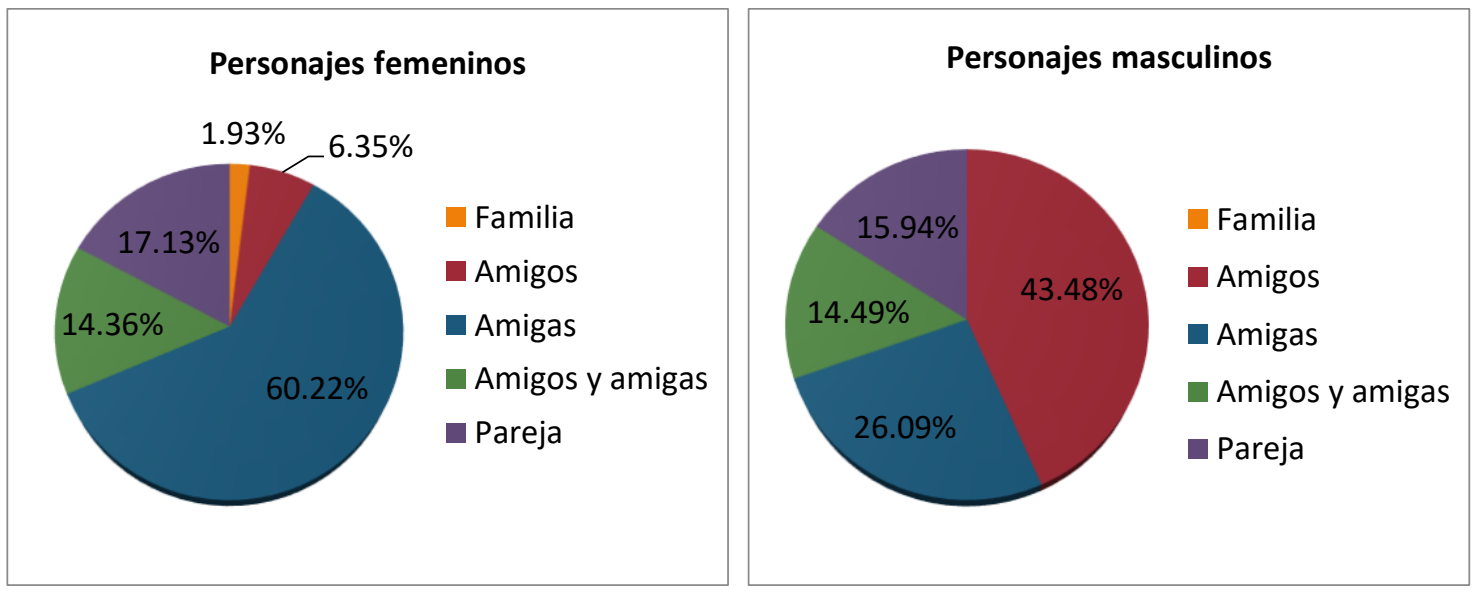

Gráfico 3. Representaciones mixtas de los personajes

Fuente: elaboración propia.

En el proceso de investigación se han detectado también dos puntos de gran interés dentro de este apartado. El primero es el cameo de la cantante Aitana en el perfil de Cristian, un personaje secundario que publicó una fotografía junto a ella ${ }^{7}$ en una fiesta acontecida en la serie. Los cameos de personajes famosos trascienden así a la ficción televisiva y se integran también en 
sus estrategias transmedia en las redes sociales. El segundo es que el 3,2\% de los contenidos con representaciones mixtas contiene nuevas huellas sociales, es decir, personajes que no aparecen en la serie. Estos perfiles ofrecen así la posibilidad de visibilizar y ampliar los marcos sociales periféricos de la diégesis, los cuales aportan referencias exclusivas que enriquecen el yo social de los personajes.

Todo este tejido de relaciones sociales, además de otorgar consistencia y coherencia a las identidades digitales de los personajes, permite establecer un sistema de sinergias comunicativas multidireccionales mediante el uso de etiquetas o la función @mention sharing en las stories. El desarrollo de sus relaciones sociales, por tanto, supone una oportunidad para redirigir de forma estratégica a los seguidores de un personaje a otro.

d) Representación de objetos: son más frecuentes en los perfiles de ellas $(15,12 \%)$ que en los de ellos $(12,45 \%)$ y suelen utilizarse para proyectar sus gustos alimentarios, sus propias creaciones, sus intereses culturales o su sentido del humor. Todos ellos se configuran como estrategias de representación alternativas similares a las que utilizan los usuarios en esta plataforma para "subvertir la idea preestablecida de que el yo es identificado principalmente por sus características físicas [...] y buscan representaciones de sí mismos a través de otro tipo de imágenes" (Caldeira, 2016, p. 151).

Mediante esta categoría de representación indirecta, se adopta un nuevo enfoque de los mundos ficcionales al explorar espacios y elementos insustanciales que habitualmente son invisibilizados en la ficción televisiva. La fotografía de una hamburguesa, un paisaje indefinido o la imagen de un muñeco, se convierten en objetos destacados que enriquecen los perfiles al aportar información específica de los personajes, reflejar sus actividades digitales y revelar lo ordinario dentro de su mundo ficcional.

\subsubsection{Contextos de las representaciones}

El marco contextual de los contenidos supone una fuente destacable de información a la hora de definir las vivencias de los personajes, sus áreas de actividad o sus estilos de vida, por un lado, y presentar el aspecto y las características del mundo ficcional en el que habitan, por otro. Así pues, según los datos obtenidos (ver gráfico 4), se detecta que ambos géneros son representados principalmente en espacios urbanos y cotidianos (hogar e instituto), siendo la mayoría escenarios desnudos que no ahondan en sus posibilidades expresivas para provocar un efecto de realidad. La experiencia de los personajes en Instagram queda ligada así a lo ordinario y lo mundano, lo cual, como apunta García (2019, p. 18), "tiene un efecto doble de proyectar autenticidad y demandar enganchamiento con la audiencia". Si hasta ahora los espacios cotidianos han venido siendo los más destacados en las teen series (García y Fedele, 2011b), con los perfiles sociales de los personajes, la ciudad se constituye como un nuevo marco de 
representación relevante en la construcción de sus identidades digitales.

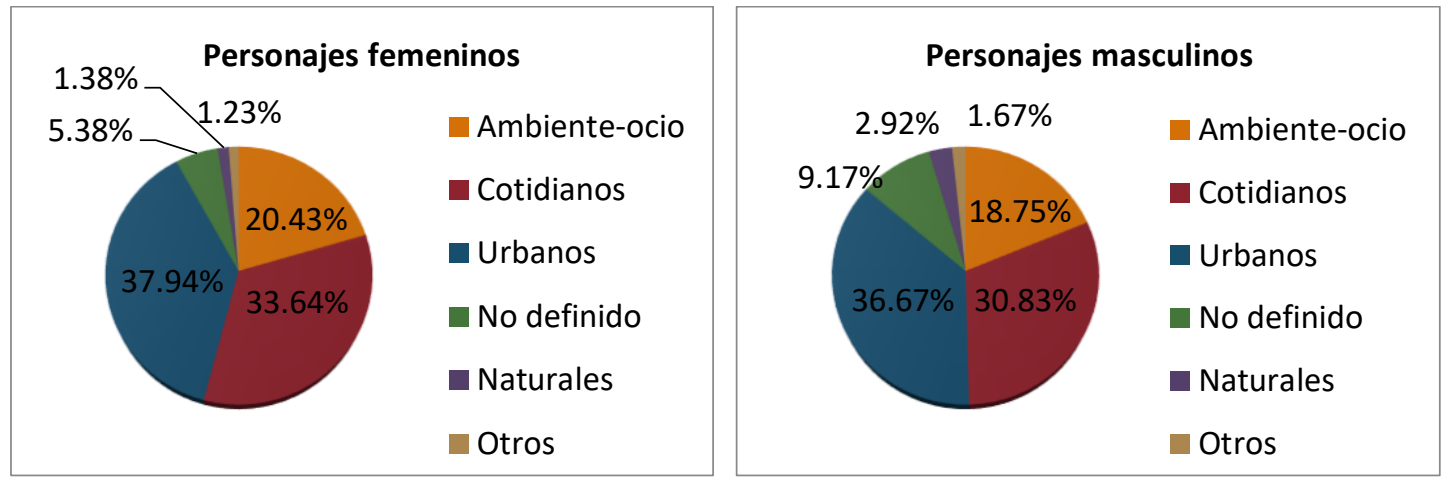

Gráfico 4. Contextos de los contenidos según el género de los personajes

Fuente: elaboración propia.

El tercer contexto más habitual en ambos géneros está relacionado con aquellos espacios de ambiente y ocio, los cuales son a menudo escenarios privilegiados para la creación de fotografías y vídeos centrados en grupos de personajes. Suelen compartir diversos contenidos en torno a un mismo evento y destinan a las stories aquellos más graciosos y divertidos, y a los perfiles los más estéticos.

Aunque los espacios situados en la urbe se erigen como los marcos contextuales nucleares de los contenidos analizados, se encuentra también un porcentaje muy reducido de entornos naturales ligados en su mayoría a momentos vacacionales de los personajes. Los espacios naturales, por tanto, quedan vinculados a experiencias extraordinarias de los personajes que suelen suceder en los márgenes de la diégesis.

En último lugar, el 5,38\% de los contenidos en los perfiles de ellas y un 9,17\% en los de ellos no ofrecen información contextual. Estos porcentajes están relacionados en su mayoría con aquellos contenidos en los que la información contextual ha sido fagocitada por la presencia corporal de los personajes representados.

\subsection{Duración y actividad promocional de los perfiles ficcionales}

Inicialmente, según su duración, se encuentra que el 57,14\% de los perfiles se ha mantenido activo durante toda la vida comercial de la serie, el $21,43 \%$ ha durado dos temporadas y otro $21,43 \%$ son perfiles eventuales ligados a una sola temporada. Estos porcentajes establecen una correlación lógica con las funciones de los personajes en las tramas, ya que los perfiles más longevos se corresponden con los personajes nucleares, principalmente femeninos, mientras que los que tienen una vida más corta son los de aquellos personajes de apoyo que actúan de catalizadores.

En cuanto a sus periodos de actividad, el $77,30 \%$ de los contenidos se ha publicado durante la emisión de cada temporada, mientras que el porcentaje restante viene a cubrir aquellos espacios intermedios entre una temporada y otra. Si bien este resultado revela una frecuencia de publicación mayor durante la emisión para reforzar la conexión de los perfiles con la narración de la ficción televisiva, se ha detectado que algunos personajes secundarios conservan 
una actividad similar (los perfiles de Alejandro, Cristian e Inés) o, incluso, superior (el perfil de Eloy) en aquellos periodos previos y posteriores a cada temporada.

Durante tales periodos transicionales, se observa además una actividad estratégica al activarse algunas cuentas en fechas importantes. Durante el $8 \mathrm{M}$ o fin de año, por ejemplo, algunos personajes compartieron fotografías participando en la manifestación o en una fiesta celebrando el año nuevo. Así pues, ante la ausencia de un mundo ficcional activo en el plano televisivo, la ficción se nutre de la propia realidad y busca escenarios comunes con su público objetivo para ocasionar un efecto de coexistencia y simultaneidad con nuestra realidad online y offline.

\section{CONCLUSIONES}

La radiografía propuesta en esta investigación indaga en la construcción de las identidades digitales de los personajes de una teen series en uno de los espacios sociales más concurridos actualmente por los jóvenes en Internet: Instagram. Dada la amplia muestra de contenidos obtenida y la diversidad de perfiles analizados, se pueden sustraer conclusiones significativas en base a los objetivos y las hipótesis planteadas.

En primer lugar, el ecosistema de contenidos compartidos apunta a la construcción de identidades digitales que connoten principalmente un uso constante de los dispositivos móviles, de ahí que las fotografías y los vídeos de producción propia sean las publicaciones más comunes. Al tratarse de un dispositivo indisociable a los jóvenes actuales, tales contenidos emanan un aire de espontaneidad y naturalidad que inunda de realismo los perfiles de los personajes. En contraste, la escasez encontrada de fragmentos procedentes de la cultura digital online revela una limitación a la hora de definir ampliamente la identidad digital de los personajes. Se puede decir así que los personajes representados crean contenidos en base a su mundo ficcional y los publican en espacios sociales online comunes a los usuarios, pero apenas comparten contenidos procedentes de los medios y la cultura digital online. La primera hipótesis, por tanto, se puede confirmar parcialmente al prevalecer la publicación de fragmentos que provocan un efecto de realismo, aunque no se ha detectado un ecosistema de contenidos especialmente diversificado.

Respecto a los múltiples arquetipos que presentan los perfiles y sus publicaciones, se obtienen varias conclusiones de interés. Desde el punto de vista sociodemográfico, aunque la serie está protagonizada por personajes femeninos, la estrategia transmedia persigue construir una imagen igualitaria al crear el mismo número de perfiles para ambos géneros. De este modo se conserva la estructura de grupo para fomentar la interacción entre los personajes, aunque los perfiles femeninos reflejan el protagonismo manteniendo una actividad mayor.

Adicionalmente, considerando las investigaciones de Guarinos (2009), Ramos y Fernández (2011), García y Fedele (2011b) y Lemoine (2013), es posible afirmar que las publicaciones de estos perfiles perpetúan los arquetipos de las teen series relacionados con los rasgos raciales, predominando los caucásicos; la religión, desconectada de todos los personajes, salvo en el caso de Amira, que expone su identidad como musulmana; y el físico, que se corresponde con los cánones estéticos más comunes, siendo ellas de complexión delgada-normal y ellos normal- 
musculoso. En cambio, desde el punto de vista de la sexualidad de los personajes, los contenidos analizados proponen un nuevo discurso al dar más visibilidad, en este caso, a las orientaciones lésbicas que a las heterosexuales.

Con todos estos datos se confirma la segunda hipótesis planteada y se puede afirmar que estos perfiles heredan y reproducen ampliamente los arquetipos analizados de los personajes de las teen series, aunque son también un espacio de representación capaz de redefinirlos.

Por otro lado, los personajes hacen visible su identidad digital de un modo continuo y fragmentado, configurando un yo fluido que se proyecta a través de representaciones directas (centradas en el yo y sus relaciones sociales) e indirectas (el otro y objetos) que conservan, principalmente, un discurrir temporal lineal. A su vez, la construcción de la identidad digital está fundamentada en una búsqueda constante de realismo y naturalidad, utilizando para ello marcos contextuales ordinarios y mundanos, siendo en este caso los espacios urbanos y cotidianos los que determinan la cotidianeidad de los personajes. Consecuentemente la tercera hipótesis propuesta queda verificada y, a la luz de los datos obtenidos en el análisis, se encuentra además que las identidades digitales de los personajes pueden estar asociadas tanto a emplazamientos publicitarios de productos como a cameos.

Más aún, los perfiles están sincronizados principalmente con el desarrollo televisivo del mundo ficcional, por lo que su actividad se concentra mayoritariamente durante la emisión y su duración está determinada por el papel que desempeña cada personaje en la serie, siendo más longevos y activos aquellos de los protagonistas. En cambio, entre temporadas, si bien los perfiles suelen entrar en un estado de hibernación hasta que se aproxima el estreno, experimentan algunas activaciones en fechas y escenarios estratégicos para conectar con su público objetivo. La última hipótesis, por tanto, queda validada también.

A modo de reflexión final, la identidad digital de los personajes ficcionales, especialmente de aquellos que representan a jóvenes, se presenta como un aspecto estratégico no solo para el desarrollo de experiencias transmedia de larga duración, sino también para explorar nuevas formas de construir y representar a personajes activos tanto en la ficción como en la realidad de los usuarios. De esta forma se pone al descubierto un amplio campo de posibilidades narrativas y promocionales para futuras ficciones televisivas.

\section{Referencias}

Bengtsson, E., Källquist, R. \& Sveningsson, M. (2018). Combining New and Old Viewing Practices: Uses and Experiences of the Transmedia Series "Skam". Nordicom Review: Nordic Research on Media \& Communication, 39(2), 63-77. doi: 10.2478/nor-2018-0012

Caldeira, S. (2016). Identities in Flux: An Analysis to Phographic Self-Representation on Instagram. Observatorio, 10(3), 135-158. doi: 10.15847/obsOBS10320161031

Cantón, F. (2019). Socialización digital y creatividad audiovisual: construcción social de la imagen a través de Instagram (Tesis doctoral). Universidad de Granada. Recuperado de: https://bit.ly/2WCBYQ7

Caro, L. (2012). La encarnación del yo en las redes sociales digitales: identidad mosaico. Telos: Cuadernos de comunicación e innovación, 91, 59-68. 
Cortés, S., Martínez, R. \& De la Fuente, J. (2016). Contribución de las redes sociales a la creación de narrativas transmedia a partir de las series de ficción en televisión. Comunicación y hombre, 12,153-176.

Costa, Carmen (2013). Narrativas Transmedia Nativas: Ventajas, elementos de la planificación de un proyecto audiovisual transmedia y estudio de caso. Historia y Comunicación Social, 18(no extra 3), 561-574. doi: 10.5209/rev_HICS.2013.v18.44349

Dena, C. (2009). Transmedia Practice: Theorising the Practice of Expressing a Fictional World across Distinct Media and Environments. (Tesis doctoral). University of Sydeny. Recuperado de: https://bit.ly/2CtKZni

Evans, E. (2011). Transmedia Television. Audiences, New Media and Daily Life. New York: Routledge.

García, N. \& Fedele, M. (2011a). Las series televisivas juveniles: tramas y conflictos en una "teen series". Comunicar: Revista científica iberoamericana de comunicación y educación, 19(37), 133-140. doi: 10.3916/C37-2011-03-05

García, N. \& Fedele, M. (2011b). Retrato de los adolescentes en la ficción televisiva. Un estudio de caso. Ámbitos: Revista internacional de comunicación, no20, pp. 71-86.

García, V. (2019). Estética del sujeto hipermediatizado. Edición, estilización y curación del yo en la red. ASRI. Arte y Sociedad. Revista de información, 17, 12-24.

Gauthier, P. (2018). Inmersion, social media and transmedia storytelling: the "inclusive" mode of recepction. Comunicación y Medios (37), 11-23. doi: 10.5354/0719-1529.2018.46952

Grandío, M. \& Bonaut, J. (2012). Twitter y el consumidor implícito en la ficción televisiva. La narración crossmedia al servicio del branding creativo. En M. A. Nicolás y M. M. Grandío (Coords.), Estrategias de comunicación en redes sociales: usuarios, aplicaciones y contenidos (pp. 121-137). Barcelona: Gedisa.

Guarinos, V. (2009). Fenómenos televisivos "teenagers": prototipias adolescentes en series vistas en España. Comunicar: Revista científica iberoamericana de comunicación y educación, 17(33), pp. 203-211. doi: 10.3916/c33-2009-03-012

IAB Spain (2019). Estudio anual de redes sociales 2019. Recuperado de https://bit.ly/2WVReGE

Lacalle, C. (2013). Jóvenes y ficción televisiva. Construcción de identidad y transmedialidad. Barcelona: UOC Press.

Lemoine, E. (2013). La construction de l'adolescenc-e américain-e dans les séries télévisées (1990-2010) (Tesis doctoral). Université François Rabelais de Tours. Recuperado de: https://bit.ly/3fSQdYF

Leonardo, N. (2019). Teoría de la selfi. Narrativa y usos de la fotografía digital contemporánea. DeSignis: Publicación de la Federación Latinoamericana de Semiótica, 30, 115-122. doi: http://dx.doi.org/10.35659/designis.i30p115-122

Merino, L. (2011). Jóvenes en redes sociales: significados y prácticas de una sociabilidad digital. Revista de Estudios de la Juventud, 95, 31-43.

Ortega, E. (2019). El lenguaje social de la ficción televisiva y sus antihéroes: "La quinta pared en House of Cards" (Tesis doctoral). Universidad Complutense de Madrid. Recuperado de: https://bit.ly/2X54JE6

Ramos, A. \& Fernández, J. (2011). Ficcionar al otro: imaginarios, inclusión y presencia de las minorías religiosas en las series de ficción españolas. Razón y palabra, 78.

Rustad, G. (2018). Skam (NRK, 2015-17) and the rhythms of reception of digital television. Critical Studies in Television: The International Journal of Television Studies, 13(4), 505-509. doi: 10.1177/1749602018796755 
Sabina, J., De la Fuente, J. \& Martínez, R. (2019). El ecosistema mediático juvenil en España: un estudio de caso sobre el fandom de la serie Skam. En N. López y E. Medina (Coords.), Comunicación y Pensamiento. Relatos de la nueva comunicación (pp. 33-52). Sevilla: Ediciones Egregius.

Scolari, C. (2013). Lostology: Transmedia storytelling and expansion/compression strategies. Semiotica, 195, 45-68. doi: 10.1515/sem-2013-0038

Sibilia, P. (2013). La intimidad como espectáculo. Buenos Aires: Fondo de Cultura Económica.

Zaccone, E. (2011). TV Series and Social Network Marketing: The Audiovisual Text as a Wider Experience. En M. Pérez (coord.), Previously on: estudios interdisciplinarios sobre la ficción televisiva en la Tercera Edad de Oro de la Televisión (pp. 387-402). Sevilla: Biblioteca de la Facultad de Comunicación de la Universidad de Sevilla.

Zimmermann, A. (2015). Blurring the Line Between Fiction and Reality. Functional Transmedia Storytelling in the German TV Series About:Kate. Image, 22, 22-35. Recuperado de: https://bit.ly/2LzQBNU

Notas

${ }^{1}$ Esta investigación ha sido financiada por el Proyecto nacional I+D+i "JUVEN-TV. Nuevos consumos frente a viejos estereotipos: análisis de la recepción por parte de la juventud española de sus representaciones televisivas actuales" (CSO2017-85483-R).

Esta investigación forma parte de los resultados del Proyecto de I+D CSO2017-85483-R "JUVEN-TV. Nuevos consumos frente a viejos estereotipos: análisis de la recepción por parte de la juventud española de sus representaciones televisivas actuales", financiado por el Ministerio de Ciencia, Innovación y Universidades.

${ }^{2}$ Disponible en https://bit.ly/2yV9WGN.

${ }^{3}$ Disponibles en https://bit.ly/3fSPTZX.

${ }^{4}$ Disponibles en https://bit.ly/2z3tKYo.

5 Cada temporada de Skam España está enfocada en un personaje femenino diferente. Consecuentemente este porcentaje podría aumentar en la próxima temporada que será protagonizada por Amira.

${ }^{6}$ Disponibles en https://bit.ly/3bCYfBC.

${ }^{7}$ Disponible en https://bit.ly/31fzylu. 